\title{
Ecological and life history traits explain a climate induced shift in a temperate marine fish community
}

\author{
Mc Lean Matthew James ${ }^{1,{ }^{*}}$, Mouillot David ${ }^{2}$, Auber Arnaud ${ }^{1}$
}

${ }^{1}$ IFREMER, Unité Halieutique de Manche et mer du Nord, 150 quai Gambetta, BP699, 62321

Boulogne-sur-Mer, France

${ }^{2}$ MARBEC, Université de Montpellier, CNRS, IFREMER, IRD, 34095 Montpellier Cedex, France

* Corresponding author : Matthew James Mc Lean, email address : mcleami@gmail.com

\begin{abstract}
:
A better understanding of community dynamics and ecosystem functioning can be achieved by describing how community functional structure responds to environmental change over both time and space and by identifying which functional groups best mediate community responses. Here, we used a trait-based approach in combination with a newly developed application of principal response curves to functionally characterize a rapid taxonomic shift in the eastern English Channel fish community in the late 1990s. We identified the functional groups with the greatest contributions to the overall shift in fish functional structure and uncovered significant trait-environment relationships. We found that pelagic species with rapid life history cycles, characterized by broadcast spawning, small offspring size, and early maturation, declined considerably in abundance following an increase in sea surface temperature associated with a warming phase of the Atlantic Multidecadal Oscillation, which was likely exacerbated by historical fishing pressure. In contrast, species with late maturation, high parental care, and few, welldeveloped offspring increased in abundance, reinforcing that fish community responses to climate warming are strongly mediated through life history traits. By examining how environmental factors drove a community shift at the trait level, we provide a mechanistic understanding of how fish functional structure responds to rapid environmental change.
\end{abstract}

Keywords : Atlantic Multidecadal Oscillation, Climate warming, English Channel, Functional ecology, Principal response curves, Response traits 


\section{Introduction}

41 Sustainably managing natural resources requires a greater understanding of community dynamics

42 and ecosystem functioning under changing environmental conditions (Kremen 2005, Carpenter et

43 al. 2009, Cheung et al. 2016). Examining community dynamics on a species by species basis is

44 useful for stock assessments and population management; however, such taxonomic approaches

45 are less insightful for understanding ecological mechanisms and processes (Díaz \& Cabido 2001,

46 Mcgill et al. 2006, Mouillot et al. 2013). By contrast, trait-based ecology links community

47 dynamics and ecosystem processes by identifying how organismal traits respond to

48 environmental change (Mcgill et al. 2006, Winemiller et al. 2015, Gross et al. 2017), which can

49 generate predictive relationships that are not taxon or ecosystem specific (Díaz \& Cabido 2001,

50 Lavorel \& Garnier 2002, Winemiller et al. 2015). This approach has gained progressive support

51 and is now recognized as an essential step forward in community ecology and natural resource

52 management (Hooper et al. 2005). Thus, a better understanding of community dynamics can be

53 achieved by describing how community functional structure responds to environmental factors

54 over both time and space, and identifying which ecological traits best mediate community

55 responses.

56 Rapid and pronounced shifts in community structure have been documented in many

57 ecosystems worldwide and are often related to rapid environmental change (Scheffer \& Carpenter

58 2003, Beaugrand 2004, Verges et al. 2014, Wernberg et al. 2016). In fish communities, such

59 shifts have been documented in response to extreme climatic events and climate cycles that alter

60 sea surface temperatures and oceanographic processes. For example, Wernberg et al. (2016)

61 documented an increase in subtropical fishes following a heatwave along southwestern Australian

62 and Reid et al. (2001) documented an increase in horse mackerel landings following a phase 
63 change of the North Atlantic Oscillation. Fluctuations of sardine and anchovy landings have also

64 been linked to alternating cycles of the Pacific Decadal Oscillation (Chavez et al. 2003,

65 Lindegren et al. 2013). Yet, such community shifts are classically examined using taxonomic 66 approaches, which are limited in explaining biological responses and their consequences for 67 ecosystem functioning (Reid et al. 2001, Chavez et al. 2003, Clare et al. 2015). Auber et al. 68 (2015) previously documented a rapid shift in the Eastern English Channel fish community in 69 response to a warming phase of the Atlantic Multidecadal Oscillation (AMO), which induced 70 substantial decreases in the abundance of several dominant species and moderate increases in 71 some subordinate species. Such taxonomy-based findings can describe major ecosystem changes 72 with potential impacts on ecosystem services but cannot identify the functional mechanisms that 73 underpin how and why certain organisms respond strongly to climatic changes while others are 74 unaffected. Rather, greater understanding of fish community responses to rapid environmental 75 change could be achieved by functionally characterizing community shifts and identifying the 76 most responsive functional groups.

While a better understanding of community shifts can be achieved by describing spatio78 temporal changes in functional groups, statistical methods for such studies are limited (Leps et al. 79 2006, Petchey \& Gaston 2006, Violle et al. 2007). Auber et al. (2017) recently proposed a new 80 application of Principal Response Curves (PRC) for examining community shifts between time 81 frames. PRC is a multivariate method that simultaneously describes spatial and temporal changes 82 in community structure and identifies the most responsive species (Van den Brink \& Ter Braak 83 1999, Auber et al. 2017). Despite the utility of PRC for describing community shifts, this method 84 has been largely underused and has not yet been applied to ecological traits. 
Here we used a trait-based approach with PRC to functionally characterize the shift in the

86 Eastern English Channel fish community, specifically answering i) did changes in taxonomic

87 community structure correspond to a pronounced shift in functional structure, ii) which functional

88 groups were most contributive to overall changes in functional structure, and iii) which

89 environmental factors were most associated to changes in functional structure through time? By

90 examining the underlying functional changes behind the taxonomic shift, we provide a

91 mechanistic understanding of changes in fish functional structure in response to rapid

92 environmental warming.

93

94 Methods

\section{Fish community data}

96 The fish community of the Eastern English Channel (EEC, area VIId defined by the International

97 Council for the Exploration of the Sea, ICES) has been sampled every October since 1988 during

98 the Channel Ground Fish Survey (CGFS). Here, we focused on the study period of $1988-2011$.

99 The CGFS sampling scheme is spatially stratified by subdividing the EEC into $15^{\prime} \times 15^{\prime}$

100 rectangles where at least one 30-min haul is made during daylight hours at an average speed of

1013.5 knots. A high (3 m) vertical opening bottom trawl (GOV) with a 10-mm-stretched-mesh-size

102 codend is used. The stratified sampling scheme manages to complete 90 to 120 hauls per year

103 depending on weather conditions, and we removed all sites that had not been visited for at least

104 three consecutive years (Auber et al. 2017). After each haul, all captured fishes are identified and

105 the number of individuals per species is counted. Abundance indices at each sampling station 
106 were obtained from the ICES data portal and were standardized to numbers of individuals per $107 \mathrm{~km}^{2}(\mathrm{ICES})$.

109 Ecological traits

110 Ecological trait data for 73 taxa (67 species and 6 genera not identified to species level) were

111 collected from FishBase (Froese \& Pauly 2012), the Ocean Biogeographic Information System

112 (http://www.iobis.org/), the Global Biodiversity Information Facility (https://www.gbif.org/),

113 Engelhard et al. (2011), Pecuchet et al. (2017), and a search of primary literature. Nine ecological

114 traits were used for this study related to life history, habitat use, and trophic ecology (Table 1).

115 Traits were chosen if they were i) readily available, ii) deemed accurate by comparison of

116 multiple sources and iii) potentially implicated in the response of communities to environmental

117 change. Categorical or binary traits included parental care, water column position, and trophic

118 guild, while continuous traits included length and age at maturity, fecundity, offspring size,

119 temperature preference, and trophic level. Temperature preference was calculated as the median

120 temperature of a species across its global range of observations for which data were available.

122 Table 1. Ecological traits and their corresponding functional groups (i.e., trait attributes).

\begin{tabular}{ll}
\hline Ecological Trait & Functional (Trait) Groups \\
\hline Length at Maturity $(\mathrm{cm})$ & $2.65-11.03,11.04-18.69,18.70-26.63,26.64-40.13, \geq 40.14$ \\
Age at Maturity (years) & $0.33-1.39,1.40-2.31,2.32-2.99,3.0-4.49, \geq 4.5$ \\
Parental Care & Pelagic Egg, Benthic Egg, Clutch Hider, Live Bearer \\
Offspring Size (mm) & $0.34-0.89,0.90-1.09,1.10-1.39,1.40-2.67, \geq 2.68$ \\
$\begin{array}{l}\text { Fecundity } \\
\text { Water Column Position }\end{array}$ & Demersal, Reef-Associated, Benthopelagic, Pelagic \\
(Engelhard et al. 2011) & \\
$\begin{array}{l}\text { Temperature Preference } \\
\left({ }^{\circ} \mathrm{C}\right)\end{array}$ & $4.62-10.41,10.42-11.29,11.30-11.72,11.73-12.49, \geq 12.5$ \\
Trophic Guild & Detritivore, Planktivore, Benthivore, Carcinophage, Benthopiscivore, Piscivore \\
Trophic Level & $2.2-3.23,3.24-3.39,3.4-3.69,3.7-3.99, \geq 4$ \\
\hline
\end{tabular}


125 When combining species' abundances and traits, ecologists generally have two choices:

126 calculate community-weighted mean (CWM) trait values or use the abundances of functional

127 groups. The advantage in using CWM trait values is that continuous data are not broken into

128 categories and thus no information is lost, however examination of the underlying changes in trait

129 values is not possible. For instance, CWM trait values could reveal that, on average, maximum

130 length of fishes decreased over time, but could not reveal whether this was driven by an increase

131 in small fishes, a decrease in large fishes, or both. In order to characterize the EEC fish

132 community shift in terms of changes in the actual abundance of different functional groups, we

133 categorized continuous traits, making all traits categorical. Continuous traits were therefore put

134 into five groups by using quintiles of the continuous trait data for all individuals with each trait

135 (Table 1). The abundances of all functional groups (i.e., each trait category or attribute) were then

$136 \log 10(\mathrm{x}+1)$ transformed.

\section{Environmental factors}

139 Environmental factors included both ocean-wide climate oscillations and local environmental

140 parameters. The North Atlantic Oscillation (NAO) is an intra-decadal alternation of atmospheric

141 mass over the North Atlantic, which is known to influence sea surface temperatures (SST) and

142 oceanographic processes (Dickson 2000). The NAO index used here is based on the difference of

143 normalized sea-level atmospheric pressure between Lisbon, Portugal and Reykjavik, Iceland

144 (Dickson 2000). The annual NAO index for the period 1988-2011 was obtained from NOAA

145 (https://www.ncdc.noaa.gov/teleconnections/nao/). The Atlantic Multidecadal Oscillation (AMO) 
146 refers to a 60-80 year cycle of North Atlantic SST (Edwards et al. 2013). The AMO index is

147 computed as a monthly area-weighted mean of SST anomalies over the North Atlantic (from 0 to

$14870^{\circ} \mathrm{N}$ ), which is detrended to remove the effect of global warming. This index is correlated to air

149 temperature and rainfall over the Northern hemisphere, and positive phases are associated with

150 warm, dry conditions, while negative phases are associated with cool, wet conditions (Enfield et

151 al. 2001). AMO values were also derived from NOAA, US

152 (https://www.esrl.noaa.gov/psd/data/timeseries/AMO/).

153 Local environmental parameters included SST, salinity, chlorophyll- $a$, and dissolved

154 oxygen. Mean annual SST data were derived from the Hadley Centre for Climate Prediction and

155 Research's freely available HadISST1 database (Rayner et al. 2003). Mean annual chlorophyll- $a$

156 data came from the Sir Alister Hardy Foundation for Ocean Science's Continuous Phytoplankton

157 Recorder database (SAHFOS). Surface salinity and dissolved oxygen were extracted from

158 outputs of the NORWegian ECOlogical Model (http://www.ii.uib.no/ morten/norwecom.html,

159 Skogen et al. 1995). NORWECOM is a coupled 3D physical, bio-chemical model for the North

160 Sea and the English Channel that provides monthly averages of environmental parameters at a

161 geographical resolution of 0.1 degree. For salinity and dissolved oxygen, data were averaged 162 across months and spatial locations to obtain mean annual values for the entire EEC. Non-algal

163 suspended matter was obtained from satellite data (Gohin 2011) for each survey, which were then

164 averaged across years to obtain mean annual values.

\section{Fishing pressure}

167 Fishing pressure was assessed using three different fishing mortality indices: $\mathrm{F}_{\text {pelagic }}, \mathrm{F}_{\text {demersal }}$, and

$168 \mathrm{~F}_{\text {benthic }}$, for pelagic, demersal and benthic species, respectively. These were estimated annually as 169 the 1-year-lagged landing-weighted average fishing mortality rates for stocks assessed by ICES 
170 working groups, namely mackerel and herring for pelagic, cod and whiting for demersal, and

171 plaice and sole for benthic. The fishing mortality rates of these 6 stocks (the only stocks

172 analytically assessed in the EEC) were considered representative of the global fishing pressure on

173 the EEC fish community, as these species account for more than $60 \%$ of total landings in the

174 EEC (Auber et al. 2015). The 1-year lagging accounted for the fact that annual instantaneous

175 fishing mortality rates of a given year are expected to affect the abundance of fish stocks the year

176 after (Auber et al. 2015). Each fishing mortality index was calculated as the average fishing

177 mortality of the two corresponding stocks weighted by their landings. We considered pelagic,

178 demersal and benthic fishing mortality to account for mixed types of fishing gear, and to

179 encompass the totality of fishing pressure throughout all habitat zones in the EEC. The EEC is a

180 mixed-gear fishery where pelagic stocks are generally targeted by midwater trawls and demersal

181 and benthic stocks are targeted by a mix of otter trawls, beam trawls, nets, pots, and dredges

182 (Pascoe \& Coglan 2002, Ulrich et al. 2002). Thus by computing three different fishing mortality

183 indices, we account for fishing pressure across several stocks and gear types, within the

184 limitations of ICES-assessed stocks. Fishing mortality rates of the different stocks, as well as

185 landing statistics, were extracted from the ICES Stock Assessment Summary database and Catch

186 Statistics database (http://www.ices.dk/marine-data/dataset-collections/Pages/Fish-catch-and187 stock-assessment.aspx).

188

189 Data Analysis

190 Principal Response Curves 
191 Temporal and spatial changes in fish functional structure were assessed using Principal Response

192 Curves (PRC). PRC is a special case of partial redundancy analysis (pRDA) with a single tested

193 factor as the explanatory variable and a single dimension of repeated observations as the co-

194 variable (Van den Brink \& Ter Braak 1999). Auber et al. (2017) recently adapted the PRC

195 analysis to examine spatiotemporal changes in community structure, specifically between two

196 time periods (i.e., a 'baseline period' and a 'tested period'), by using spatial sites as repeated

197 observations and time as a tested factor. The PRC analysis generates canonical regression

198 coefficients $\left(c_{d t}\right)$ for each sampling site, as well as contribution weights $\left(b_{k}\right)$ for each species (or

199 functional group in this study). The absolute values of canonical coefficients $c_{d t}$ quantify, at each

200 sampling site, the magnitude of change between the two tested time periods, and the absolute

201 values of functional group weights $b_{k}$ quantify the contribution of each functional group to the

202 overall change of community structure; groups with weights near zero have little or no response,

203 while groups with high weights have strong responses. For a given functional group; the sign (+/-

204 ) of the canonical coefficients $c_{d t}$ indicates the type of community response and is interpreted by

205 comparing with the sign (+/-) of weights $b_{k}$. When the signs of $b_{k}$ and $c_{d t}$ coefficients are

206 identical, the abundance of the corresponding functional group is higher in the tested period than

207 the baseline period, and when the signs of $b_{k}$ and $c_{d t}$ are opposite the abundance is higher in the

208 baseline period than the tested period. For a complete description of the original PRC method and

209 the new application of the PRC, see Van den Brink \& Ter Braak (1999) and Auber et al. (2017).

210 In correspondence with the taxonomic community shift in the EEC (Auber et al. 2015),

211 we considered the years 1988 to 1997 as the pre-shift period (baseline period), and 1998 to 2011

212 as the post-shift period (tested period). We then applied the PRC analysis to examine changes in 
213 functional community structure at each site between the two time periods, and to identify the

214 functional groups with the highest contributions to overall change. The PRC analysis was

215 performed using the function prc in the $\mathrm{R}$ package vegan. Significant changes in functional

216 structure between the two periods were then tested at each sampling site using Monte-Carlo

217 permutation tests designed to correct for the increase in the family-wise type 1 error rate due to

218 multiple comparisons across sampling sites (see Auber et al. [2017] for full details and R code).

\section{Influence of environmental factors and fishing mortality}

221 We identified the influences of environmental factors on temporal changes in fish functional

222 structure using RLQ and fourth corner analyses, where we considered environmental factors

223 across years rather than across sites. RLQ is a method that integrates environmental data (R),

224 species abundance data (L), and species' ecological traits (Q) to examine how environmental

225 factors influence trait variation (Dray et al. 2014). RLQ examines the co-inertia between three

226 separate ordination analyses (i.e., R, L, and Q), while fourth-corner analysis assess statistical

227 associations between each environmental factor and each functional group individually (Dray \&

228 Legendre 2008, Dray et al. 2014). Thus RLQ analysis was first used to reveal major

229 environmental drivers of temporal variation in fish functional structure, while fourth corner

230 analysis then identified significant correlations between individual functional groups and

231 environmental factors. For both the RLQ and fourth corner analyses, species abundance data

232 were the mean time series of species composition averaged over the entire EEC, thus the species

233 abundance table (L) consisted of species mean abundances in columns and years in rows. While

234 RLQ is generally applied to spatial data, as the analysis functions through co-inertia of three 
235 individual ordinations, alternative species abundance structures, including temporal, are

236 permissible (see Dolédec et al. 1996, Dray \& Legendre 2008). Temporal environmental drivers

237 included in RLQ analysis were mean annual AMO, NAO, SST, salinity, chlorophyll- $a$, oxygen,

238 and fishing mortality (pelagic, demersal, and benthic). Thus the environmental table consisted of

239 mean environmental factors in columns and years in rows. A potential concern with RLQ and

240 fourth corner analysis was the influence of temporal autocorrelation among variables.

241 Autocorrelation can bias statistical tests by inflating type-1 error, leading to spurious correlations.

242 However, RLQ analysis is purely descriptive and does not test for significant relationships (see

243 Thuiller et al. 2006). To account for potential autocorrelation in fourth corner analysis, which

244 does test for significant relationships, we used both the standard fourth corner analysis and an

245 extended version of fourth corner that integrates Moran spectral randomization to account for

246 autocorrelation (Wagner \& Dray 2015). MSR is a constrained randomization procedure that

247 compares observed values against a null model that preserves the autocorrelation of the data

248 (Wagner \& Dray 2015). Due to missing environmental data in 2009, 2010, and 2011, RLQ and

249 fourth corner analysis were calculated for the time series $1988-2008$.

\section{Results}

252 The PRC analysis revealed that sampling sites explained 34\% of spatio-temporal variance in fish

253 functional structure (horizontal axis Fig. 1a), while time explained $13.4 \%$, $71 \%$ of which is

254 represented by the first canonical axis of the PRC analysis (vertical axis Fig. 1a). All sites in the

255 EEC were characterized by positive $c_{d t}$ values, indicating that the type of community change was

256 the same at every site (Fig. 1a). However, $c_{d t}$ values were highly variable across sites, indicating 
that while all sites experienced the same type of change, the magnitude of change was spatially

258 heterogeneous (Fig. 1a,b). Monte-Carlo permutation tests further revealed that 36 out of 79 sites

259 had a significant change in fish functional structure between the two time periods (Fig. 1b).

(a)

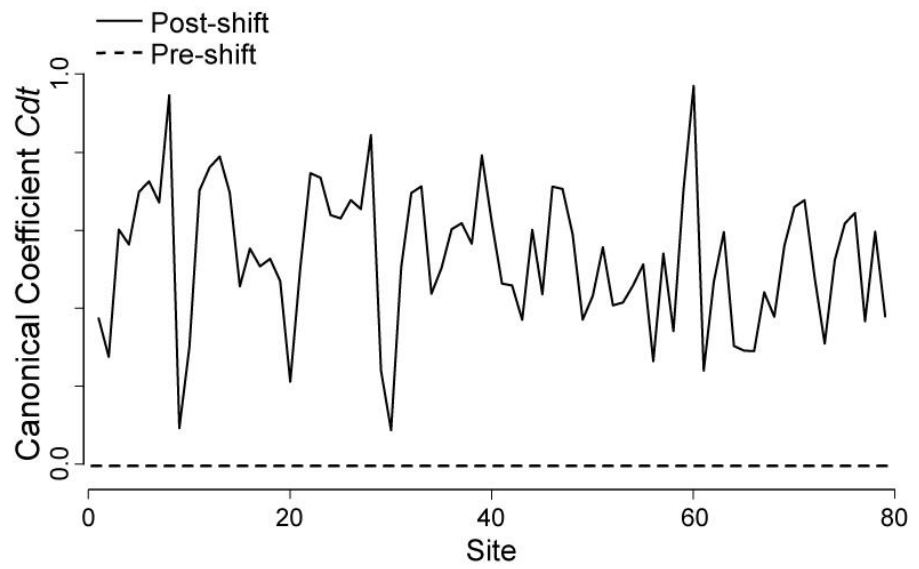

(b)
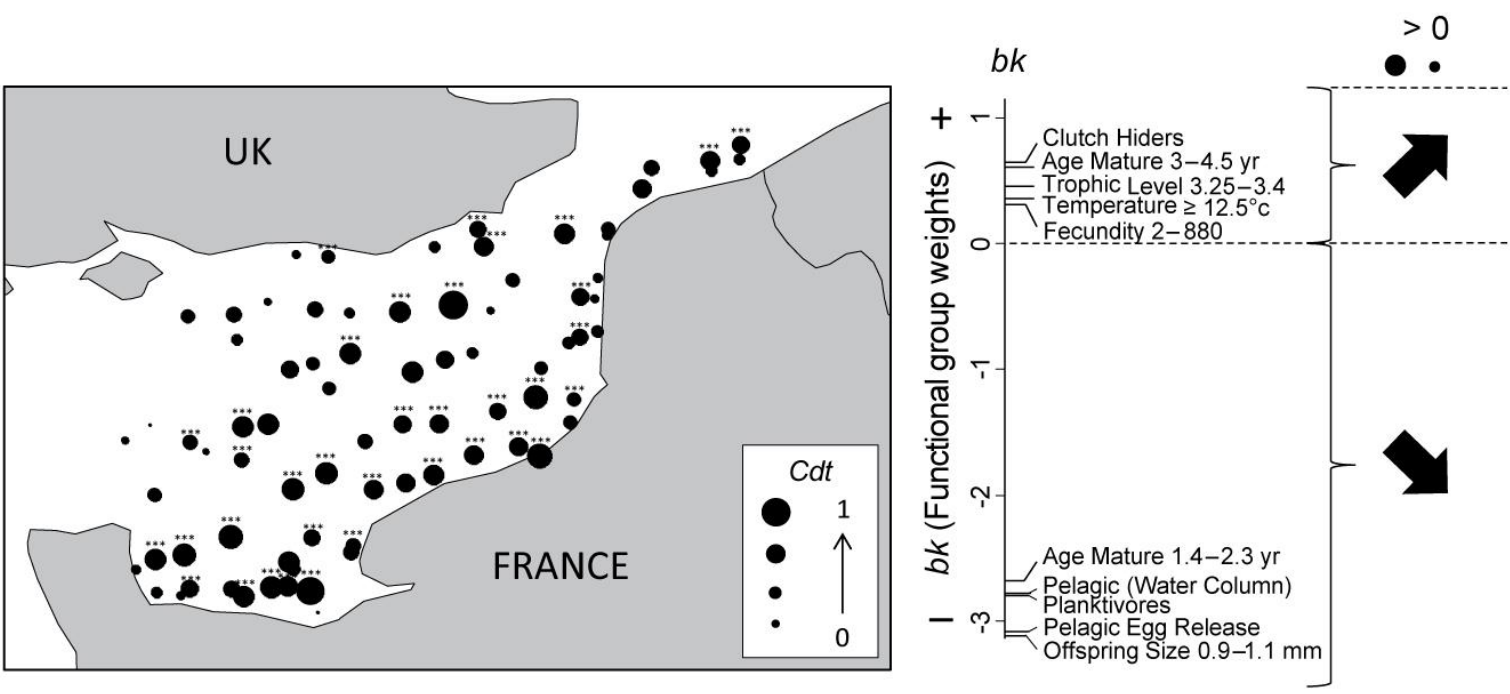

Figure 1. a) Principal Response Curve (PRC) showing changes in fish community structure across sampling sites between the baseline period [1988-1997] (pre-shift) and tested period [1998-2011] (post-shift), with the most contributive functional groups ranked by their $b_{k}$ coefficients. For clarity, only traits with $b_{k}$ coefficients in the first or last decile are shown. b) Map showing the amplitude of temporal changes in fish functional structure (i.e., $c_{d t}$ values) at each sampling site and the trend (increase or decrease) of abundance for each functional group. $0.01 ; *: 0.01<\mathrm{p}<0.05)$. 
Functional group weights $b_{k}$ revealed that changes in fish functional structure were

272 primarily driven by decreases in species with small offspring size $(0.9-1.1 \mathrm{~mm})$, pelagic egg

273 release (broadcast spawning), planktivory, pelagic water column position, and low age at

274 maturity (1.4 - 2.3 years), as the absolute values of $b_{k}$ were much higher for functional groups

275 with negative values (decreasing) (Fig. 1). Concurrently, there was an increase in clutch hiders

276 (i.e., high parental care) and species with high age at maturity ( $3-4.5$ years), moderate trophic

277 level $(3.25-3.4)$, high temperature preference $\left(\geq 12.5^{\circ} \mathrm{C}\right)$, and low fecundity $(2-880)$ (Fig. 1).

278 Thus, the taxonomic shift in the EEC fish community in the late 1990's was generally

279 characterized by a strong decrease in pelagic and planktivorous species with opportunistic, ' $\mathrm{r}$ -

280 selected' life history traits, and a moderate increase in species with equilibrium, 'K-selected' life

281 history traits.

282

283 Influence of environmental factors

284 RLQ analysis identified AMO, demersal and pelagic fishing mortality, SST, and NAO as the 285 primary drivers of temporal variability in fish functional structure, as AMO and fishing mortality

286 had the highest correlations with the first RLQ axis, and SST and NAO were both highly 287 correlated with the first RLQ axis and had the highest correlations with the second RLQ axis 288 (Figure 2, Figure 3). 
(a)

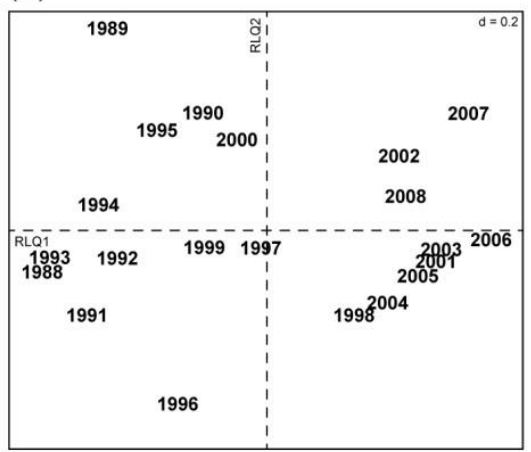

(b)

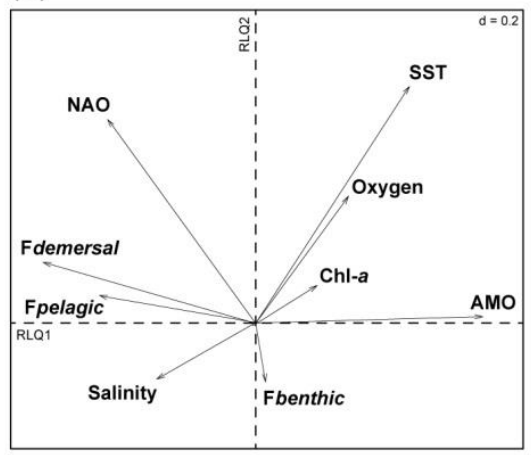

(c)

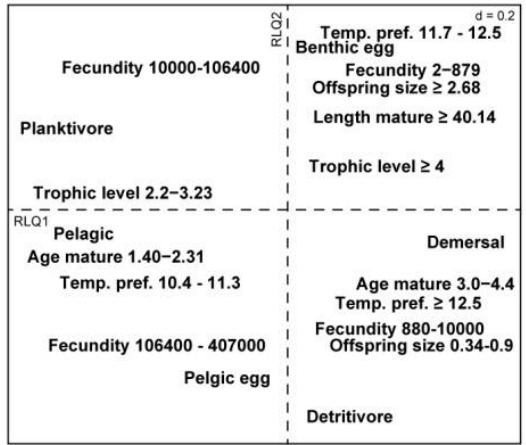

291

(a)

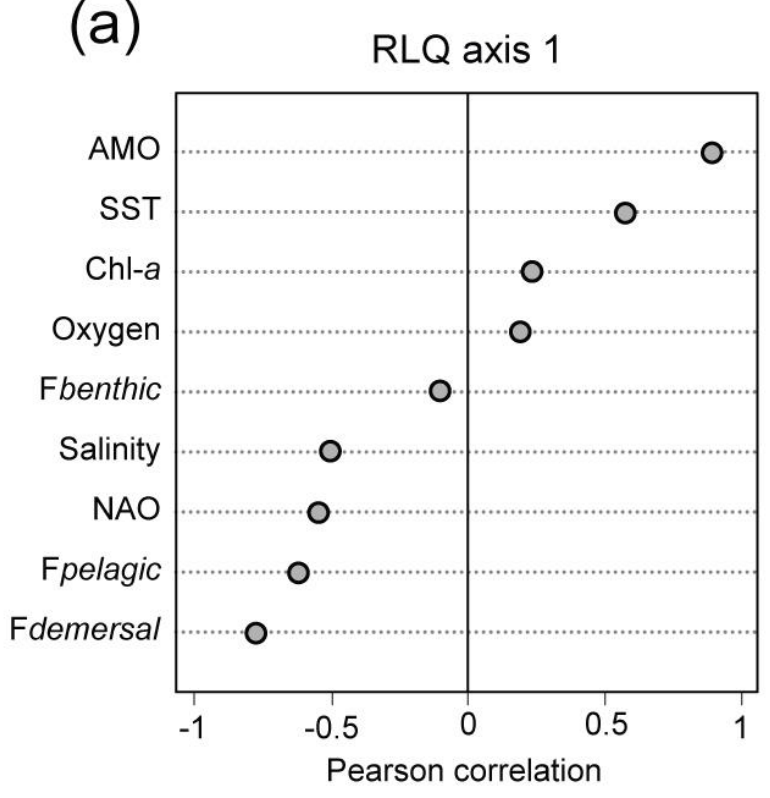

(b)

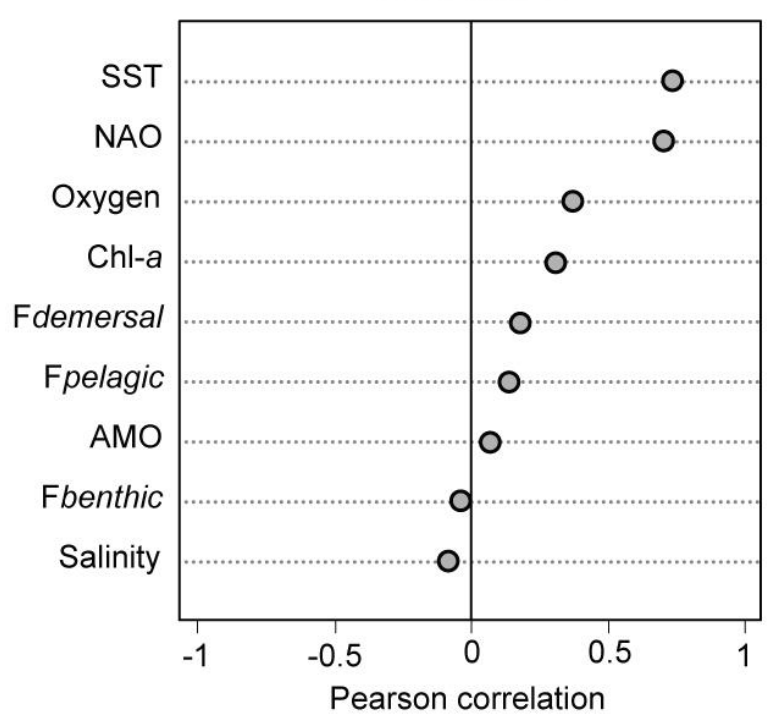

Figure 2. RLQ biplots showing temporal (a) associations between environmental factors (b) and functional groups (c). For clarity, only functional groups with the greatest correlations (first or last decile) to the first and second RLQ axes are plotted (b). Environmental factor acronyms: Atlantic Multidecadal Oscillation (AMO), sea surface temperature (SST), chlorophyll- $a$ (Chl- $a$ ), pelagic fishing mortality $\left(\mathrm{F}_{\text {pelagic }}\right)$, demersal fishing mortality $\left(\mathrm{F}_{\text {demersal }}\right)$, benthic fishing mortality $\left(\mathrm{F}_{\text {benthic }}\right)$. Temp. pref. = temperature preference. The first two RLQ axes preserved $87 \%$ of environmental variation and $71 \%$ of trait variation.

300 Figure 3. Contribution of environmental factors to temporal variation in fish functional structure according to Pearson correlations between environmental factors and the first (a) and second (b) axes of the RLQ analysis. Environmental factor acronyms: Atlantic Multidecadal Oscillation (AMO), North Atlantic Oscillation (NAO), sea surface temperature (SST), chlorophyll- $a$ (Chl- $a$ ), 
304 pelagic fishing mortality $\left(\mathrm{F}_{\text {pelagic }}\right)$, demersal fishing mortality $\left(\mathrm{F}_{\text {demersal }}\right)$, benthic fishing mortality $305\left(\mathrm{~F}_{\text {benthic }}\right)$.

Initial fourth corner analysis, without MSR, indicated that AMO had positive

relationships with demersal species and species with high age at maturity ( $3-4.5$ years), and negative relationships with pelagic and planktivorous species and species with low trophic level

310 (2.2 - 3.25), low age at maturity (1.4 - 2.3 years), and low temperature preference $(10.4-$

$\left.31111.3^{\circ} \mathrm{C}\right)(\mathrm{p}<0.05$, Fig. 4). In contrast, NAO was positively correlated with planktivores and

312 negatively correlated with species with high temperature preferences $\left(\geq 12.5^{\circ} \mathrm{C}\right)$. SST was

313 positively correlated with species with the largest length at maturity $(\geq 40.1 \mathrm{~cm})$, lowest fecundity

$314(2-880)$, largest offspring size $(\geq 2.7 \mathrm{~cm})$, and reef-associated species, and negatively correlated

315 with species with low temperature preference $\left(10.4-11.3^{\circ} \mathrm{C}\right)(\mathrm{p}<0.05$, Fig 4$)$. Dissolved oxygen

316 had a single, positive association with high trophic level species $(\geq 4)(p<0.05$, Fig 4). Pelagic

317 and demersal fishing mortality had nearly identical relationships with functional groups; however

318 pelagic mortality had fewer significant associations. Both pelagic and demersal mortality were

319 positively associated with pelagic and planktivorous species, and negatively associated with

320 demersal species and species with high age at maturity $(3-4.5$ years $)(p<0.05$, Fig 4$)$. Demersal

321 fishing mortality was also positively related to species with the lowest trophic level $(2.2-3.25)$

322 and lowest age at maturity $(1.4-2.3$ years) $(\mathrm{p}<0.05$, Fig 4$)$. However, re-running the fourth

323 corner analysis with MSR to account for temporal autocorrelation revealed that only AMO and

324 SST had significant associations with any of the functional groups, indicating potential spurious

325 correlations for fishing mortality, oxygen, and NAO due to high autocorrelation (Fig 4). The

326 relationships between AMO, SST, and functional group dynamics remained nearly identical, with 

preference no longer significant.

(a)

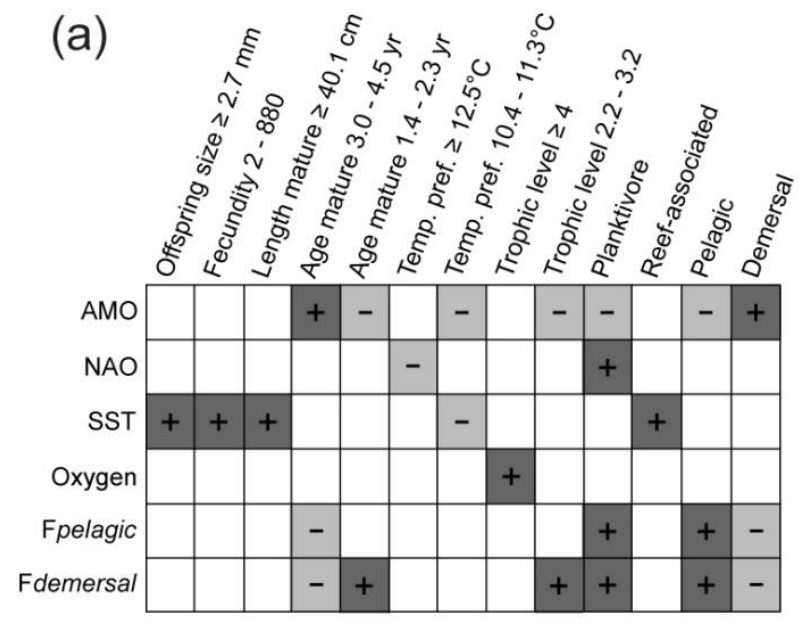

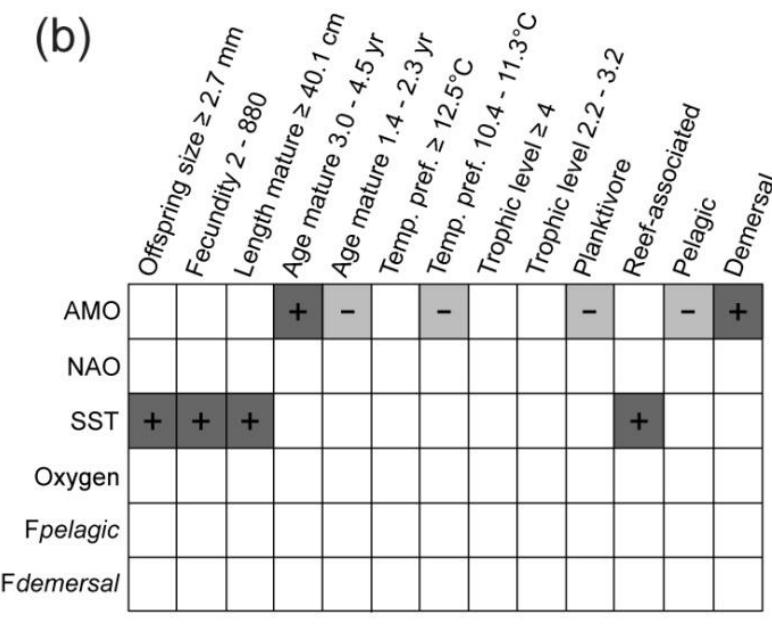

331

332

333

334

335

336

337

338

339

340

341

342

343

344

Figure 4. Results of fourth corner analyses of trait-environment correlations without (a) and with (b) Moran spectral randomization (white $=$ no significant relationship, dark grey $=$ positive relationship, light grey $=$ negative relationship. Environmental factor acronyms: Atlantic Multidecadal Oscillation (AMO), North Atlantic Oscillation (NAO), sea surface temperature $(\mathrm{SST})$, pelagic fishing mortality $\left(\mathrm{F}_{\text {pelagic }}\right)$, demersal fishing mortality $\left(\mathrm{F}_{\text {demersal }}\right)$. Temp. pref. $=$ temperature preference.

(1)

\section{Discussion}

Here, we found that a previously documented taxonomic shift in a temperate marine fish community also corresponded to a considerable shift in fish functional structure. This is a major finding as community functional structure can be relatively unaffected by temporal species replacement or turnover (Villéger et al. 2010, Clare et al. 2015). Examining the taxonomic shift through the lens of ecological traits provided more pronounced results and greater insight into the biological mechanisms behind the shift. We found that the shift was characterized by a large 
345 decrease in the abundance of pelagic, planktivorous species with low temperature preferences and

346 opportunistic, 'r-selected' life histories such as low age and size at maturity and low trophic level,

347 and a concurrent increase in species with moderate to high temperature preferences and

348 equilibrium, 'K-selected' life histories such as high size and age at maturity, few large offspring,

349 and high parental care. Interestingly, we found significant temporal change in functional

350 community structure at roughly half of all sites (36 of 79), whereas Auber et al. (2017) found

351 significant temporal change for only 13 sites when using PRC with taxonomic data, highlighting

352 that changes in community structure are better identified using ecological traits regardless of

353 species identity.

354 The finding that the type of community change was similar across all sites indicates a

355 regionally-consistent response across the entire EEC. Indeed, we found that changes in fish

356 functional structure are strongly correlated with the Atlantic Multidecadal Oscillation and

357 associated increases in sea surface temperature. While sea surface temperature has been

358 progressively rising in the North Atlantic during the past few decades, the switch from a cool to a

359 warm phase of the AMO lead to unusually-rapid warming (Ting et al. 2009, Moore et al. 2017).

360 This rapid warming likely amplified ongoing 'tropicalisation' throughout the Channel, causing an

361 abrupt decrease of species sensitive to higher sea surface temperatures, and a concurrent increase

362 in tolerant species (Rijnsdorp et al. 2009, Cheung et al. 2013, Verges et al. 2014). Indeed, we

363 identified increases in species with high temperature preferences as contributive to the overall

364 change in fish functional structure, and also identified correlations between AMO, SST, and

365 temperature preference. While the North Atlantic Oscillation (NAO) was also correlated to

366 changes in fish functional structure, the NAO is a regional index of atmospheric pressure that was

367 associated with ocean warming in the late-1980s (Reid et al. 2001), but has progressively

368 declined in parallel to the AMO increase. 
370 analysis also identified substantial correlation between fishing mortality and functional group

371 dynamics. However, both demersal and pelagic fishing pressure declined in parallel to decreasing

372 fish abundances, and both fishing indices had identical relationships with the abundance of small

373 pelagic fishes. Thus, fishing mortality was likely not a primary driver of changes in fish

374 functional structure, as pelagic fishing mortality declined in parallel to a pronounced decrease in

375 small pelagic fishes. The community shift being characterized by a rapid decrease in species with

376 fast life history cycles also indicates an environmental response rather than progressive fishing

377 impacts (Perry et al. 2005, Rijnsdorp et al. 2009). However, given that demersal fishing pressure

378 was positively correlated with pelagic and planktivorous fishes and negatively correlated with

379 demersal fishes, it is likely that historically high demersal fishing increased the relative

380 abundance of pelagic fishes with rapid growth and generation times, rendering the community

381 more susceptible to climate stress (Thurstan et al. 2010, Molfese et al. 2014, Auber et al. 2015,

382 McLean et al. In press). Indeed the English Channel has been heavily exploited for decades,

383 particularly following intense industrialization of commercial fisheries in the early to mid-1900s

384 (Pauly et al. 2002). Long-term overfishing and fishing down the food web in the English Channel

385 have progressively shifted the ecosystem from historical dominance by large demersal species

386 such as cod and ling toward increased dominance by small pelagic and demersal species with

387 higher fishing tolerances, and commercially-untargeted species like catsharks (McHugh et al.

388 2011, Molfese et al. 2014). Thus, while the rapid shift in fish functional structure appeared most

389 strongly associated with climate-driven ocean warming, the long history of exploitation in the

390 EEC clearly reinforced this shift by rendering the ecosystem susceptible to a climatic disturbance.

391 Furthermore, the observed functional shift also reflects reduced contemporary fishing effort, as

392 we observed an increase in larger and higher trophic level species through time (Pauly et al. 
393 2002). Altogether it appears that historical overfishing in combination with rapid environmental

394 change induced a major shift in fish functional structure, as the EEC was dominated by species 395 with environmentally-sensitive life history traits in the early 1990s, which were highly responsive 396 to the shift in AMO.

While high temperature preference was identified as an influential trait, temperature 398 preference is a 'soft' (i.e., easily measured but less informative) trait that serves as a proxy for 399 'hard' (i.e., informative but difficult to measure) physiological traits influencing species' 400 distributions and habitat preferences (Leps et al. 2006, Violle et al. 2007, Pakeman 2011). More 401 interesting was the finding that increasing and decreasing species contrast strongly in life history 402 traits related to offspring survival, population growth, and generation time. Species with $\mathrm{r}$ 403 selected life histories follow type III survivorship curves, where many small offspring are 404 produced and given little to no parental investment (Pianka 1970, Gadgil \& Solbrig 1972, 405 Southwood et al. 1974). This strategy employs the trade-off that while survivorship is extremely 406 low among progeny, larval dispersal and population turnover are high, allowing populations to 407 quickly respond to unfavorable environmental conditions (Pianka 1970, Gadgil \& Solbrig 1972, 408 Southwood et al. 1974). Alternatively, K-selected strategists make large energetic investments in 409 few, well-developed offspring. While such a strategy limits dispersal and colonization abilities, 410 progeny are strong competitors and have high individual fitness (Pianka 1970, Gadgil \& Solbrig 411 1972, Southwood et al. 1974). Beyond the classical distinction of $\mathrm{r}$ and K-selected strategies, 412 recent work using ecological traits suggests a continuum of three life history strategies where r413 selected species are considered 'opportunistic' and K-selected species can be split into 'periodic' 414 and 'equilibrium' based on tradeoffs in fecundity, parental care, and offspring size (Winemiller \& 415 Rose 1992, King \& McFarlane 2003, Pecuchet et al. 2017). Opportunistic species are 416 characterized by low size and trophic level and short lifespans, but with high fecundity 
417 (Winemiller \& Rose 1992, King \& McFarlane 2003, Pecuchet et al. 2017). Both periodic and

418 equilibrium species have larger size, higher trophic level, and longer lifespans, but periodic

419 species have high fecundity and low parental care, whereas equilibrium species have low

420 fecundity and high parental care (Winemiller \& Rose 1992, King \& McFarlane 2003, Pecuchet et

421 al. 2017). In the context of the three-strategy life history continuum, our results suggest that

422 opportunistic species are the most susceptible to rapid environmental change, notably warming,

423 due to their shorter life cycles, while equilibrium species with few, well-developed offspring and

424 longer life cycles, appear less responsive. Prior studies examining the relationship between life

425 history strategies and climate change have shown that opportunistic species can be highly

426 impacted by climate warming because short generation times enable rapid population responses

427 (Jiguet et al. 2007, Hoffmann \& Sgro 2011, Pearson et al. 2014). For example, Perry et al. (2005)

428 and DeVictor et al. (2012) documented faster and more pronounced distribution shifts among

429 species with faster life cycles and smaller size in fishes, birds and butterflies, while Simpson et al.

430 (2011) showed that smaller fish species responded faster to warming across European shelf seas.

431 While prior studies have documented rapid responses in opportunistic species, few 432 examples have shown that such responses can drive major community shifts in entire species 433 assemblages over large temporal and spatial scales (Perry et al. 2005, Devictor et al. 2012). Here, 434 our results suggest that temperature warming, amplified during the late 1990s by the combination 435 of man-made climate change and the AMO (Ting et al. 2009), led to an abrupt decrease in 436 opportunistic species with fast life histories throughout the EEC, likely as an evolutionary 437 response to a rapidly changing environment (Pianka 1970, Stearns 1989, Bradshaw \& Holzapfel 438 2006). It further appears that this decrease allowed equilibrium species to expand their 439 populations under new environmental conditions. However, although opportunistic species are 
440 highly responsive to environmental change and can thus be heavily impacted over short time-

441 scales, over evolutionary time opportunistic species should have higher capacity to adapt given

442 their rapid evolutionary responses (Rijnsdorp et al. 2009).

443 Among potential explanations for the shift in functional structure, temperature rise likely

444 affected larval and juvenile mortality rates through changes in dispersion and recruitment

445 (Blaxter 1991, Drinkwater et al. 2014, Young et al. 2018) or through match-mismatches with

446 food sources (Kristiansen et al. 2011, McQueen \& Marshall 2017). Additionally, as proposed by

447 Auber et al. (2015), this community shift may have been influenced by density-dependent

448 interactions such as predation and competition. Temperature rise is also known to drive species

449 emigrations, and the community shift could have resulted from the rapid displacement of existing

450 individuals (Day et al. 2018, Pinsky et al. 2013, McLean et al. In press). Finally, while

451 opportunistic species can rapidly track environmental changes, allowing quick recovery when

452 conditions return to normal, the community has not returned to the initial pre-shift state,

453 suggesting environmental conditions are no longer favorable for the impacted species, inhibiting

454 their recovery.

455 While we found interesting patterns linking ecological and life history traits to rapid 456 environmental change, our study has several important limitations. As we examined changes in 457 the abundance of functional groups, our results are influenced by both trait choice and 458 categorization (Leps et al. 2006, Mcgill et al. 2006, Violle et al. 2007). Such methods remain 459 subjective, and there is no universal approach for choosing traits or defining groups. Binning 460 species also leads to a necessary loss of trait information and can potentially combine species 461 with different environmental responses. Our approach further cannot account for intra-specific 462 trait variability, and thus cannot examine how changes in ontogeny or population demographics 
463 influence functional structure (Petchey \& Gaston 2006, Violle et al. 2007). We also used RLQ

464 analysis to examine the potential drivers of temporal changes in fish functional structure;

465 however RLQ is unable to identify statistical significance due to potential autocorrelation, and

466 can only reveal associations among variables.

467 By using a trait-based approach, we were able to uncover the ecological characteristics

468 linking species that drove a rapid shift in the EEC fish community. These findings increase our

469 understanding of how organisms respond to environmental change and help anticipate how

470 ecosystems might change in the future. Growing evidence shows it is essential to adopt a trait-

471 based approach as it provides better understanding of biological mechanisms and because global

472 change will have drastic impacts on biodiversity, which will be mediated through species'

473 functional characteristics.

\section{Author contributions}

476 AA and MM conceived the ideas and designed the methodology. MM analyzed the data and led

477 the writing of the manuscript. DM played an advisory role, reviewed the methods and results, and

478 revised the manuscript. All authors contributed critically to the drafts and gave final approval for 479 publication.

\section{Acknowledgements}

482 The authors thank all scientists that contributed to this work, especially those who participated in 483 the CGFS monitoring campaigns between 1988 and 2011. This study was supported by 
484 Électricité de France (RESTICLIM and ECLIPSE project), IFREMER (ECLIPSE project),

485 Région Hauts-de-France and the Foundation for Research on Biodiversity (ECLIPSE project, 486 contract no. astre 2014-10824).

\section{References}

Auber A, Travers-Trolet M, Villanueva MC, Ernande B (2015) Regime Shift in an Exploited Fish Community Related to Natural Climate Oscillations. PLoS One 10

Auber A, Travers-Trolet M, Villanueva MC, Ernande B (2017) A new application of principal response curves for summarizing abrupt and cyclic shifts of communities over space. Ecosphere 8:e02023

Beaugrand G (2004) The North Sea regime shift: evidence, causes, mechanisms and consequences. Prog Oceanogr 60:245-262

Blaxter J (1991) The effect of temperature on larval fishes. Neth J Zool 42:336-357

Bradshaw WE, Holzapfel CM (2006) Evolutionary response to rapid climate change. Science 312:1477-1478

Carpenter SR, Mooney HA, Agard J, Capistrano D, DeFries RS, Díaz S, Dietz T, Duraiappah AK, Oteng-Yeboah A, Pereira HM (2009) Science for managing ecosystem services: Beyond the Millennium Ecosystem Assessment. Proc Natl Acad Sci 106:1305-1312

Chavez FP, Ryan J, Lluch-Cota SE, Ñiquen M (2003) From anchovies to sardines and back: multidecadal change in the Pacific Ocean. Science 299:217-221

Cheung WW, Reygondeau G, Frölicher TL (2016) Large benefits to marine fisheries of meeting the 1.5 C global warming target. Science 354:1591-1594

Cheung WW, Watson R, Pauly D (2013) Signature of ocean warming in global fisheries catch. Nature 497:365-368

Clare DS, Robinson LA, Frid CLJ (2015) Community variability and ecological functioning: 40 years of change in the North Sea benthos. Mar Environ Res 107:24-34

Day PB, Stuart-Smith RD, Edgar GJ, Bates AE (2018) Species' thermal ranges predict changes in reef fish community structure during 8 years of extreme temperature variation. Divers Distrib 24:1036-1046 
513 Devictor V, Van Swaay C, Brereton T, Chamberlain D, Heliölä J, Herrando S, Julliard R,

$514 \quad$ Kuussaari M, Lindström Å, Roy DB (2012) Differences in the climatic debts of birds and $515 \quad$ butterflies at a continental scale. Nat Clim Change 2:121

516 Dickson R (2000) The NAO: the dominant atmospheric process affecting oceanic variability in home, middle and distant waters of European Salmon. In book: The Ocean Life of Atlantic Salmon. Fishing News Books, Blackwell Science

Díaz S, Cabido M (2001) Vive la difference: plant functional diversity matters to ecosystem processes. Trends Ecol Evol 16:646-655

Dolédec S, Chessel D, Braak CJF ter, Champely S (1996) Matching species traits to environmental variables: a new three-table ordination method. Environ Ecol Stat 3:143166

Dray S, Choler P, Dolédec S, Peres-Neto PR, Thuiller W, Pavoine S, ter Braak CJF (2014) Combining the fourth-corner and the RLQ methods for assessing trait responses to environmental variation. Ecology 95:14-21

Dray S, Legendre P (2008) Testing the species traits-environment relationships: the fourth-corner problem revisited. Ecology 89:3400

Drinkwater KF, Miles M, Medhaug I, Otterå OH, Kristiansen T, Sundby S, Gao Y (2014) The Atlantic Multidecadal Oscillation: Its manifestations and impacts with special emphasis on the Atlantic region north of 60 N. J Mar Syst 133:117-130

532 Edwards M, Beaugrand G, Helaouët P, Alheit J, Coombs S (2013) Marine ecosystem response to

Enfield DB, Mestas-Nuñez AM, Trimble PJ (2001) The Atlantic multidecadal oscillation and its the Atlantic Multidecadal Oscillation. PLoS One 8:e57212 relation to rainfall and river flows in the continental US. Geophys Res Lett 28:2077-2080

Engelhard GH, Ellis JR, Payne MR, Hofstede R ter, Pinnegar JK (2011) Ecotypes as a concept for exploring responses to climate change in fish assemblages. ICES J Mar Sci 68:580591

539 Froese F, Pauly D (2012) FishBase. www.fishbase.org (accessed Mar 2017)

540 Gadgil M, Solbrig OT (1972) The concept of r-and K-selection: evidence from wild flowers and some theoretical considerations. Am Nat 106:14-31

542 Gohin F (2011) Annual cycles of chlorophyll-a, non-algal suspended particulate matter, and $543 \quad$ turbidity observed from space and in-situ in coastal waters. Ocean Sci 7:705

544 Gross N, Le Bagousse-Pinguet Y, Liancourt P, Berdugo M, Gotelli NJ, Maestre FT (2017) 
546

547

548

549

550

551

552

553

554

555

556

557

558

559

560

561

562

563

564

565

566

567

568

569

570

571

572

573

574

575

576

577

578

Hoffmann AA, Sgro CM (2011) Climate change and evolutionary adaptation. Nature 470:479485

Hooper DU, Chapin III FS, Ewel JJ, Hector A, Inchausti P, Lavorel S, Lawton JH, Lodge DM, Loreau M, Naeem S, Setälä H, Symstad AJ, Vandermeer J, Wardle DA (2005) Effects of biodiversity on ecosystem functioning: a consensus of current knowledge. Ecol Monogr 75:3-35

Jiguet F, GADOT A, Julliard R, Newson SE, Couvet D (2007) Climate envelope, life history traits and the resilience of birds facing global change. Glob Change Biol 13:1672-1684

Kremen C (2005) Managing ecosystem services: what do we need to know about their ecology? Ecol Lett 8:468-479

Kristiansen T, Drinkwater KF, Lough RG, Sundby S (2011) Recruitment variability in North Atlantic cod and match-mismatch dynamics. PLoS One 6:e17456

Lavorel S, Garnier E (2002) Predicting changes in community composition and ecosystem functioning from plant traits: revisiting the Holy Grail. Funct Ecol 16:545-556

Lindegren M, Checkley DM, Rouyer T, MacCall AD, Stenseth NC (2013) Climate, fishing, and fluctuations of sardine and anchovy in the California Current. Proc Natl Acad Sci 110:13672

Leps J, De Bello F, Lavorel S, Berman S (2006) Quantifying and interpreting functional diversity of natural communities: practical considerations matter. Preslia 78:481-501

Mcgill B, Enquist B, Weiher E, Westoby M (2006) Rebuilding community ecology from functional traits. Trends Ecol Evol 21:178-185

McLean M, Mouillot D, Lindegren M, Engelhard G, Villéger S, Marchal P, Brind'Amour A, Auber A (In press) A climate-driven functional inversion of connected marine ecosystems. Curr Biol

McQueen K, Marshall CT (2017) Shifts in spawning phenology of cod linked to rising sea temperatures. ICES J Mar Sci 74:1561-1573

Molfese C, Beare D, Hall-Spencer JM (2014) Overfishing and the Replacement of Demersal Finfish by Shellfish: An Example from the English Channel. PLoS One 9:e101506

Moore GWK, Halfar J, Majeed H, Adey W, Kronz A (2017) Amplification of the Atlantic Multidecadal Oscillation associated with the onset of the industrial-era warming. Sci Rep $7: 40861$

Mouillot D, Graham NAJ, Villéger S, Mason NWH, Bellwood DR (2013) A functional approach reveals community responses to disturbances. Trends Ecol Evol 28:167-177 
579

580

581

582

583

584

585

586

587

588

589

590

591

592

593

594

595

596

597

598

599

600

601

602

603

604

605

606

607

608

609

610

611

612

Pakeman RJ (2011) Multivariate identification of plant functional response and effect traits in an agricultural landscape. Ecology 92:1353-1365

Pauly D, Christensen V, Guénette S, Pitcher TJ, Sumaila UR, Walters CJ, Watson R, Zeller D (2002) Towards sustainability in world fisheries. Nature 418:689-695

Pearson RG, Stanton JC, Shoemaker KT, Aiello-Lammens ME, Ersts PJ, Horning N, Fordham DA, Raxworthy CJ, Ryu HY, McNees J (2014) Life history and spatial traits predict extinction risk due to climate change. Nat Clim Change 4:217-221

Pecuchet L, Lindegren M, Hidalgo M, Delgado M, Esteban A, Fock HO, Gil de Sola L, Punzón A, Sólmundsson J, Payne MR (2017) From traits to life-history strategies: Deconstructing fish community composition across European seas. Glob Ecol Biogeogr 26:812-822

Perry AL, Low PJ, Ellis JR, Reynolds JD (2005) Climate change and distribution shifts in marine fishes. Science 308:1912-1915

Petchey OL, Gaston KJ (2006) Functional diversity: back to basics and looking forward. Ecol Lett 9:741-758

Pianka ER (1970) On r- and K-Selection. Am Nat 104:592-597

Pinsky ML, Worm B, Fogarty MJ, Sarmiento JL, Levin SA (2013) Marine taxa track local climate velocities. Science 341:1239-1242

Rayner N, Parker DE, Horton E, Folland C, Alexander L, Rowell D, Kent E, Kaplan A (2003) Global analyses of sea surface temperature, sea ice, and night marine air temperature since the late nineteenth century. J Geophys Res Atmospheres 108

Reid PC, Fatima Borges M de, Svendsen E (2001) A regime shift in the North Sea circa 1988 linked to changes in the North Sea horse mackerel fishery. Fish Res 50:163-171

Rijnsdorp AD, Peck MA, Engelhard GH, Möllmann C, Pinnegar JK (2009) Resolving the effect of climate change on fish populations. ICES J Mar Sci 66:1570-1583

Scheffer M, Carpenter SR (2003) Catastrophic regime shifts in ecosystems: linking theory to observation. Trends Ecol Evol 18:648-656

Simpson SD, Jennings S, Johnson MP, Blanchard JL, Schön P-J, Sims DW, Genner MJ (2011) Continental Shelf-Wide Response of a Fish Assemblage to Rapid Warming of the Sea. Curr Biol 21:1565-1570

Sir Alister Hardy Foundation for Ocean Science (SAHFOS). Continuous Plankton Recorder Dataset. www.cprsurvey.org (accessed Sep 2017).

Skogen MD, Svendsen E, Berntsen J, Aksnes D, Ulvestad KB (1995) Modelling the primary production in the North Sea using a coupled three-dimensional physical-chemicalbiological ocean model. Estuar Coast Shelf Sci 41:545-565 
613 Southwood TRE, May RM, Hassell MP, Conway GR (1974) Ecological Strategies and

$614 \quad$ Population Parameters. Am Nat 108:791-804

615 Stearns SC (1989) Trade-offs in life-history evolution. Funct Ecol 3:259-268

616 Thuiller W, Richardson DM, Rouget M, Procheş Ş, Wilson JRU (2006) Interactions between environment, species traits, and human uses describe patterns of plant invasions. Ecology $87: 1755-1769$

Thurstan RH, Brockington S, Roberts CM (2010) The effects of 118 years of industrial fishing on UK bottom trawl fisheries. Nat Commun 1:15

Ting M, Kushnir Y, Seager R, Li C (2009) Forced and internal twentieth-century SST trends in the North Atlantic. J Clim 22:1469-1481

Van den Brink PJ, Ter Braak CJ (1999) Principal response curves: Analysis of time-dependent multivariate responses of biological community to stress. Environ Toxicol Chem 18:138148

Verges A, Steinberg PD, Hay ME, Poore AGB, Campbell AH, Ballesteros E, Heck KL, Booth DJ, Coleman MA, Feary DA, Figueira W, Langlois T, Marzinelli EM, Mizerek T, Mumby PJ, Nakamura Y, Roughan M, Sebille E van, Gupta AS, Smale DA, Tomas F, Wernberg T, Wilson SK (2014) The tropicalization of temperate marine ecosystems: climate-mediated changes in herbivory and community phase shifts. Proc R Soc B Biol Sci 281:20140846-20140846

Villéger S, Miranda JR, Hernández DF, Mouillot D (2010) Contrasting changes in taxonomic vs. functional diversity of tropical fish communities after habitat degradation. Ecol Appl 20:1512-1522

Violle C, Navas M-L, Vile D, Kazakou E, Fortunel C, Hummel I, Garnier E (2007) Let the concept of trait be functional! Oikos 116:882-892

Wagner HH, Dray S (2015) Generating spatially constrained null models for irregularly spaced data using Moran spectral randomization methods. Methods Ecol Evol 6:1169-1178

Wernberg T, Bennett S, Babcock RC, Bettignies T de, Cure K, Depczynski M, Dufois F, Fromont J, Fulton CJ, Hovey RK (2016) Climate-driven regime shift of a temperate marine ecosystem. Science 353:169-172

Winemiller KO, Fitzgerald DB, Bower LM, Pianka ER (2015) Functional traits, convergent evolution, and periodic tables of niches. Ecol Lett 18:737-751

Young EF., Tysklind Niklas, Meredith Michael P., Bruyn Mark, Belchier Mark, Murphy Eugene 


\section{Supplemental Material}

649
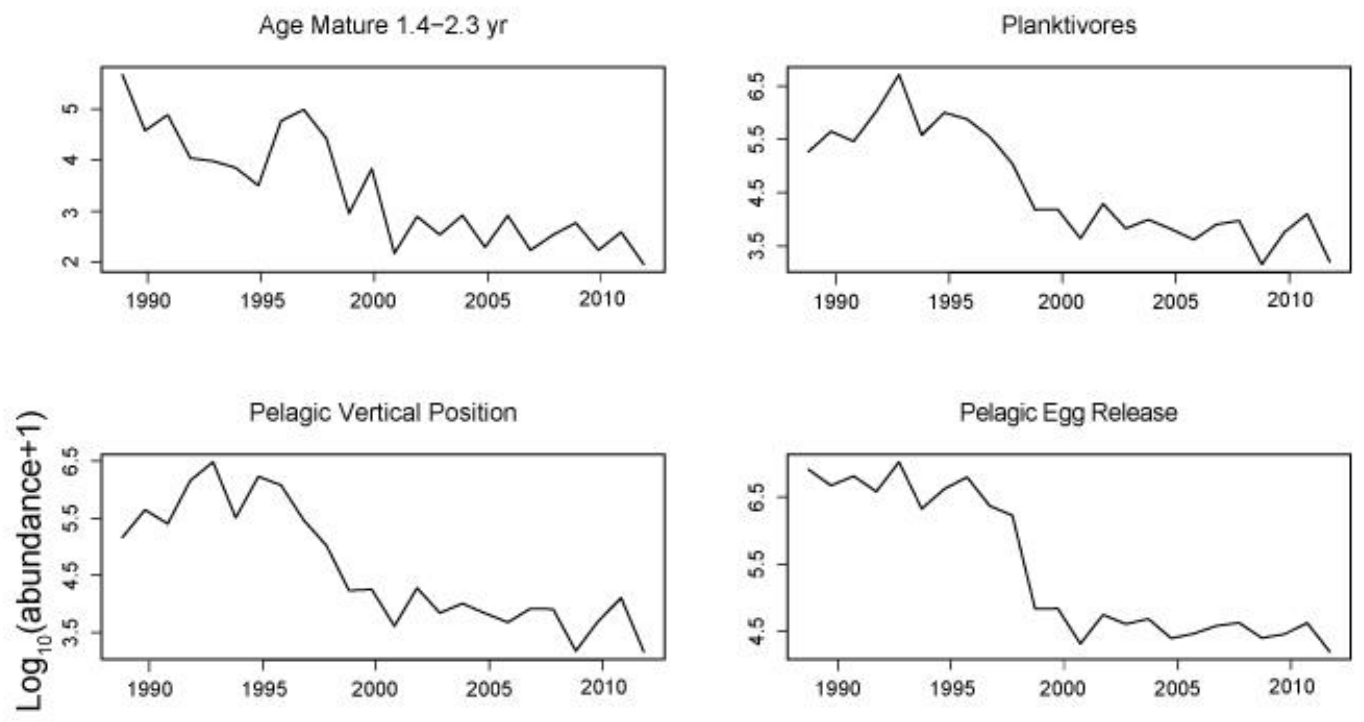

650

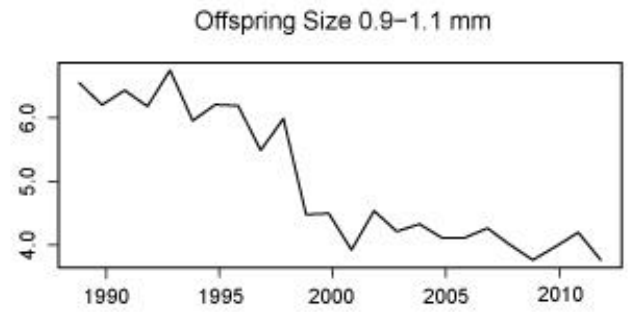

651 Supplemental Figure 1. Temporal dynamics of the most contributive functional groups that

652 decreased in abundance before and after the shift in functional structure 

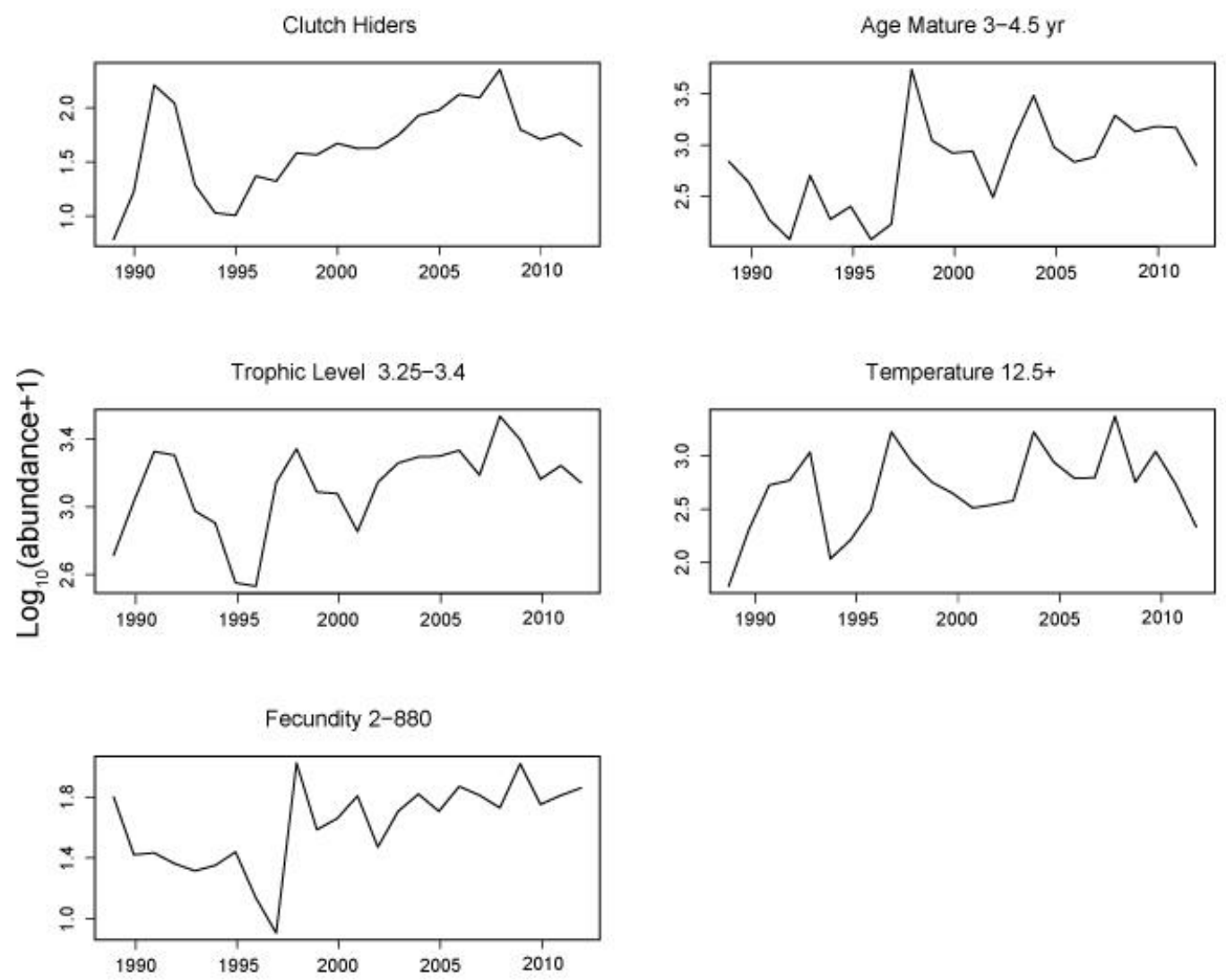

655 Supplemental Figure 2. Temporal dynamics of the most contributive functional groups that 656 increased in abundance before and after the shift in functional structure 